Carl-Mario Sultana

University of Malta

\title{
EEC Congress 2015 - Celje Slovenia
}

The Congress of the Équipe Européenne de Catéchèse (=EEC) 2015 was organized in Slovenia in the town of Celje, Slovenia's third-largest town, between $27^{\text {th }}$ May 2015 and $1^{\text {st }}$ June 2015. The theme chosen for the Congress was Conversion. The Act, The Process and Accompaniment. Many European countries were represented either through those who are responsible for catechesis in the different European nations and dioceses and/or by experts in the catechetical sphere.

The theme of Conversion was chosen because it was seen as the next logical step in the reflection of the members of the EEC following the reflection that was carried out in previous congresses which dealt with the first proclamation (2008), narrative catechesis (2010) and the languages of the faith (2012).

The Congress was introduced by an exposition on the theme and the method to be adopted by Br Enzo Biemmi, the President of the EEC. The theme proved very interesting from the very beginning. In fact, the method adopted to study the theme of conversion was not the normal deductive method. In the deductive method one commenced by studying and laying down theoretical foundations, and then later move on to more practical implications, considerations and propositions. At the Congress of Celje, the point of departure were a number of personal narratives of conversion. These were the foundations for an exercise of reflective practice that departed from actual stories of conversion and led back to how one should act in real experiences of conversion.

At the end, the entire process was one based on the method of correlation where one departs from human experience, reflects upon it with the aid of a theoretical framework, but then returned to a renewed practice. In fact, the Congress was nourished by four diverse experiences of contemporary conversions. These narrated experiences proved to be very challenging since they 
were all coming from individuals with different backgrounds and social contexts. These were to be analyzed by trying to give intelligible answers to what brought about the conversion; what helped the person during the conversion process; the relation of the individual to the Christian community; what encouraged the person to move on and ask for the Sacrament of Baptism; and to draw out the elements in the narration which give evidence of a permanent conversion.

There were two main lectures which were aimed at helping the participants in understanding and analyzing the four narratives of conversion. The first of the two inputs was by Rev. Prof. Giuseppe Laiti, entitled Stories of conversion in the first centuries of the Church. What is conversion? This lecture took the members present for a bird's eye view of narratives of conversion which have been written down and which have come to us from the first centuries of the Church. In a more specific way, Giuseppe Laiti presented the narratives of conversion of Justin the martyr, of Cyprian of Carthage, of Hilary of Poitiers and last but not least of Augustine of Hippo. Laiti was able to analyse these narratives of conversion in such a way to be able to draw out the common factors of each and every conversion. Consequently, his conclusion constituted a number of characteristics and of factors that are not only common to every conversion to Christianity, but which are also necessary for a truly Christian conversion.

The second input was by Mr Roland Lacroix from the Institut Supérieur de Pastorale Catéchétique. The lecture entitled Conversion to the Christian faith today, attempted at taking a holistic look at what is meant by conversion today. Lacroix did this in a very interesting way by looking at anthropological, at the psychological, at the anthropological and the theological approach to religious conversion. In the theological approach to conversion, Lacroix specifically highlighted conversion as a vocation and conversion as a paschal experience. $\mathrm{He}$ concluded his input by proposing the model of the catechumenate and catechesis within the catechumenate as a model for understanding and accompanying contemporary conversions.

During the Congress, there was also the possibility to visit Ljubljana. This visit was not simply a moment of rest and a downtown visit in the capital city of Slovenia. It constituted a further nourishment to the members who participated at the Congress because during the visit there was a further narrative of conversion that was different from the others presented on paper. This was a viva testimony by a Slovenian couple who converted to Christianity when they were already adults. This was complemented by an explanation of the recent 
history of Slovenia and where the Church in Slovenia stands, together with an explanation of how catechumens are accompanied in Slovenia.

The final part of the Congress was comprised of a meeting, first in small groups and then in a plenary assembly, where all those who participated were called to draw a list of reference points that could be used to accompany converts towards a permanent conversion. These were then discussed.

A very important part of the Congress was the election and presentation of the new EEC Committee. This was the last task of the meeting of the members of the EEC. The new Committee is comprised of the President: - Stijn Van den Bossche (Belgium), and of four committee members: Magda Burger (Slovenia), Jöel Molinario (France), José Maria Perez Navarro (Spain), and Salvatore Currò (Italy).

The EEC Congress of Celje proved to be a very fecund encounter that has drawn the attention of all present of the necessity of a reflective practice with regards to conversion to Christianity. The ultimate aims of the Congress were reached not only due to the expertise of the speakers involved, but also thanks to the excellent preparation made by the hosting country. 
274 Volume 6 (2016) Number 2, p. 271-276
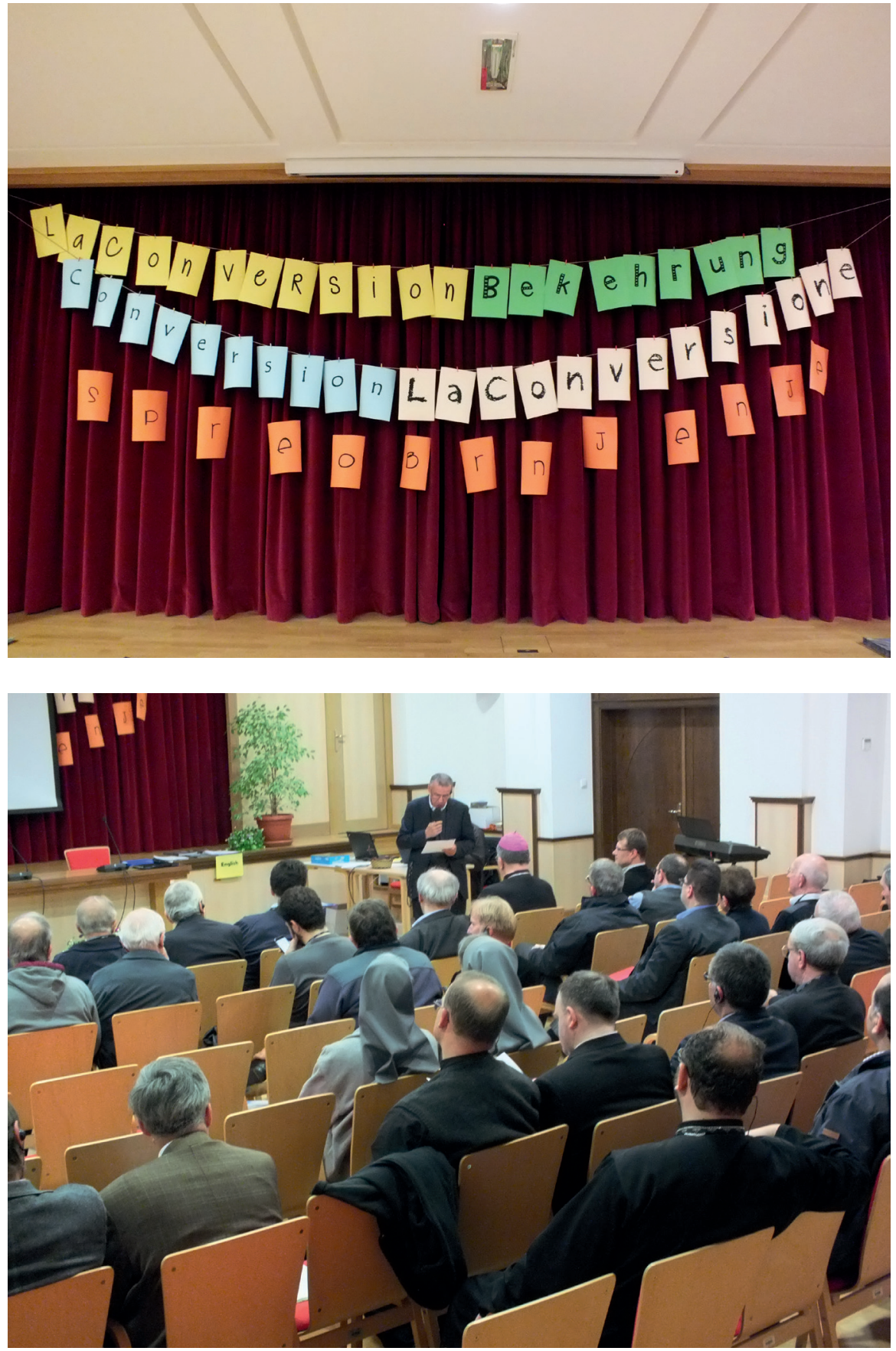

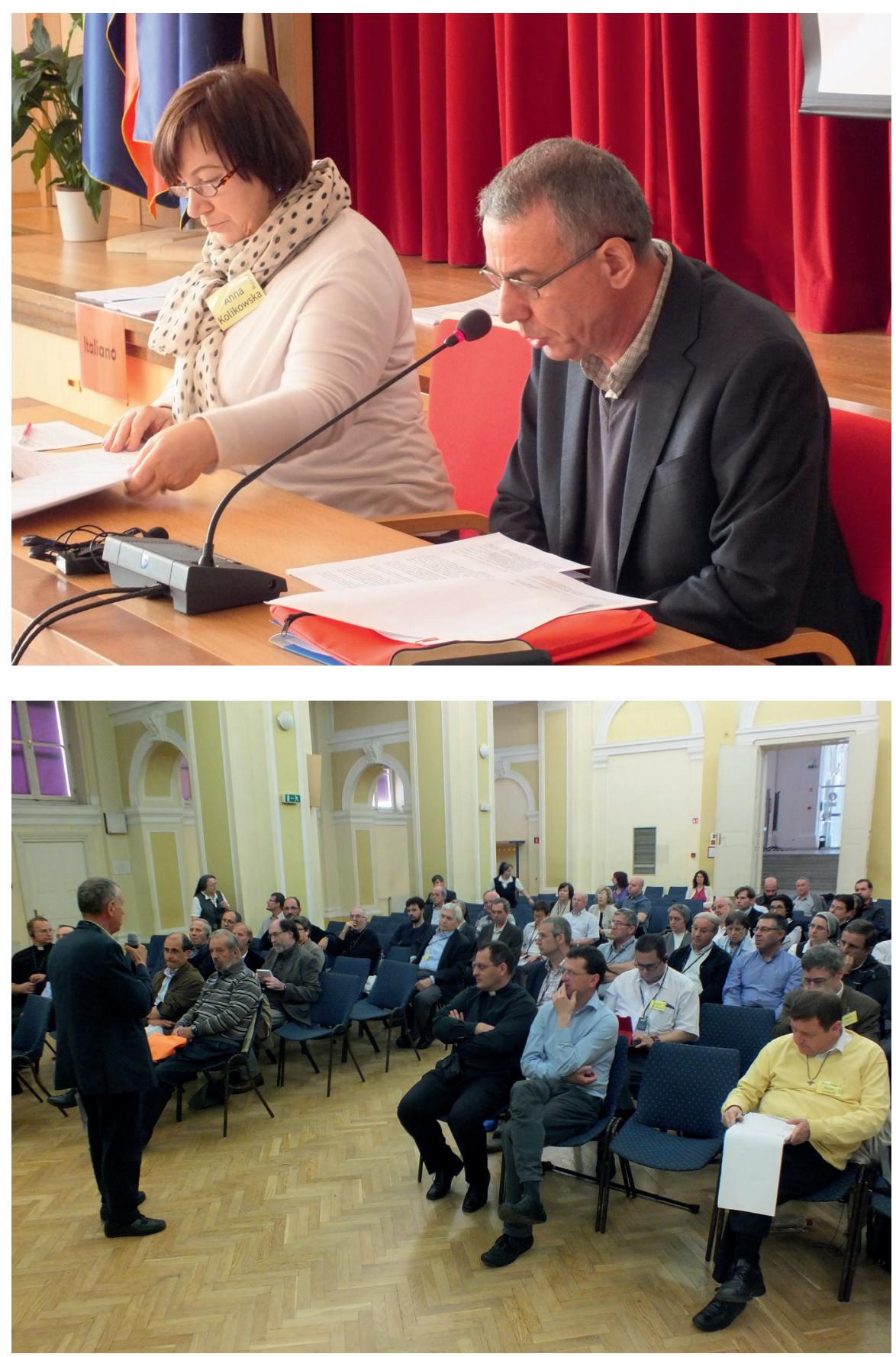
276 Volume 6 (2016) Number 2, p. 271-276
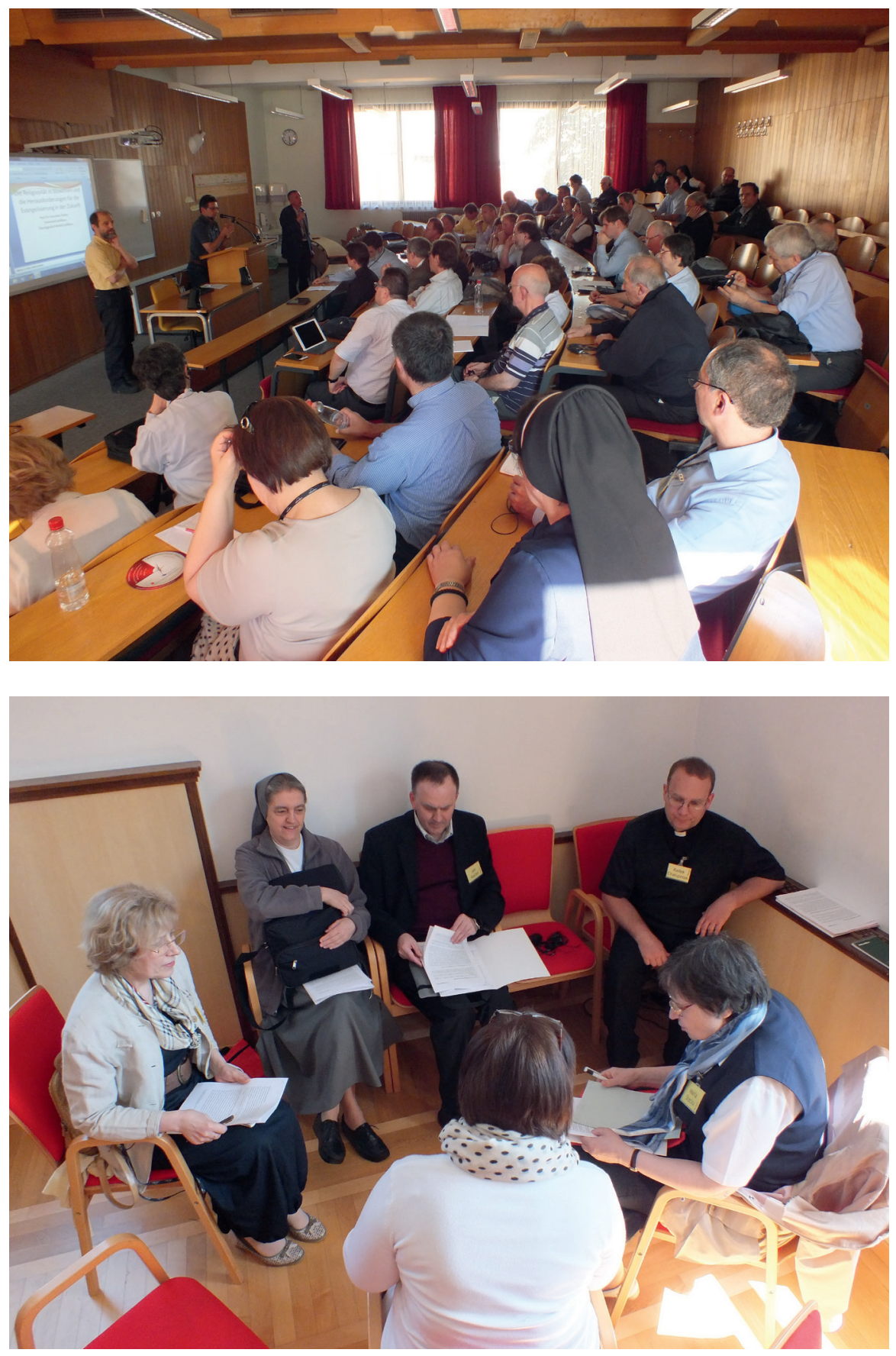